\title{
Dispersion and Damage of Carbon Nanotubes in Carbon Nanotube/7055AI Composites During High-Energy Ball Milling Process
}

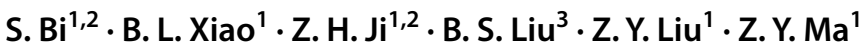

Received: 9 April 2020 / Revised: 28 June 2020 / Accepted: 7 July 2020 / Published online: 9 October 2020

(C) The Chinese Society for Metals (CSM) and Springer-Verlag GmbH Germany, part of Springer Nature 2020

\begin{abstract}
High-energy ball milling (HEBM) combined with powder metallurgy route was used to fabricate carbon nanotube (CNT) reinforced 7055 Al composites. Two powder morphology evolution processes (HEBM-1 and HEBM-2) were designed to investigate the dispersion and damage of CNTs during HEBM process. HEBM-1 evolution process involved powder flattening, cold-welding and fracture, while HEBM-2 evolution process consisted of powder flattening and fracture. For HEBM-1, the repetitive fracture and cold-welding process was effective for dispersing CNTs. However, the powder flattening process in HEBM-2 was unsuccessful in dispersing CNTs due to two reasons: (1) the thickness of flaky Al powders exceeded the critical value, and (2) the clustered CNTs embedded in flaky Al powders could not be unravelled. Because of the broadening of D band and the appearance of a new defect-related D' band, product of $I_{\mathrm{D}} / I_{\mathrm{G}}$ and full width half maximum of D band, rather than $I_{\mathrm{D}} / I_{\mathrm{G}}$, was used to evaluate the actual damage of CNTs. It indicates that the damage of CNTs was severe in powder flattening and fracture stages, while the damage of CNTs was small in powder cold-welding stage.
\end{abstract}

Keywords Metal matrix composites $\cdot$ Carbon nanotubes $\cdot$ Powder evolution $\cdot$ Dispersion and damage $\cdot$ Powder metallurgy

\section{Introduction}

Aluminium matrix composites are widely used in aerospace and automobile industries for their high modulus, good dimensional stability, wear resistance, etc. [1-4]. Among them, carbon nanotube $(\mathrm{CNT})$ reinforced aluminium matrix (CNT/Al) composites have attracted great interest for industrial application in the past decade owing to the superior mechanical properties of CNTs [5-7]. However, fabrication of the CNT/Al composites with good mechanical properties is challenging because CNTs are apt to agglomerate

Available online at https://link.springer.com/journal/40195.

Z. Y. Liu

zyliu@imr.ac.cn

1 Shi-changxu Innovation Center for Advanced Materials, Institute of Metal Research, Chinese Academy of Sciences, 72 Wenhua Road, Shenyang 110016, China

2 School of Material Science and Engineering, University of Science and Technology of China, 72 Wenhua Road, Shenyang 110016, China

3 AVIC Manufacturing Technology Institute, Beijing 100024, China and suffer damage during dispersion process [8-10]. Also, damaged CNTs easily react with aluminium during sintering process, reducing their strengthening effects $[11,12]$.

Various preparation methods like solution-assisted wet mixing [13], flake powder metallurgy [14], molecular level mixing $[15,16]$ or in situ chemical vapour deposition (CVD) $[17,18]$ have provided good solutions for dispersion with slight damage to CNTs. In the wet mixing and flake powder metallurgy process, CNTs were dispersed in water by zwitterionic or anionic surfactant and then absorbed on flake Al powders. A relatively high content of CNTs could be dispersed on flake Al powders through a preliminary highenergy ball mill (HEBM) process [19]. The molecular level mixing method involved functionalization of CNTs, coating of $\mathrm{Cu}$ on CNTs and short-time low-energy ball milling of $\mathrm{Al}$ and $\mathrm{CNT} / \mathrm{Cu}$ powders. By doing this, CNTs with large aspect ratio and minor damage were obtained [15]. In the in situ CVD process, $\mathrm{Al}$ powders coated with catalyst particles, such as $\mathrm{Co}$, were heated to an appropriate temperature in an organic atmosphere to synthesize CNTs, thereby producing mixed composite powders with uniformly distributed and undamaged CNTs. However, these chemical dispersion methods were limited to small-scale laboratory research and not applicable to industrial production. 
In comparison with the above methods, HEBM is an efficient method for dispersing CNTs and has the potential for mass production of CNT/Al powders. During HEBM process, tangled CNTs are broken by repeated collision of milling balls. It is commonly believed that the powder evolution during HEBM involves initial flattening, cold-welding, equilibrium of fracture and cold-welding. Considering the complexity of powder morphology evolution during HEBM, the contribution of each stage of HEBM to the dispersion of CNTs is still unclear. It has been claimed that CNTs were dispersed in initial flattening stage because flake Al powders had large specific surface area [20,21], whereas Choi et al. [22] believed that CNTs were dispersed through subsequent deformation of flake $\mathrm{Al}$ powders. It is still necessary to understand the effect of different HEBM stages on the dispersion of CNTs.

At the same time of dispersing CNTs, HEBM could also cause structural damage of CNTs. It is necessary to reduce the damage of CNTs while dispersing them. Although the phenomenon that CNT damage increased as milling time increased has been frequently reported [21, 23-25], there were few reports on the damage degree of CNTs in different stages of HEBM. In-depth understanding of CNT damage during various HEBM stages is still highly required.

CNT/Al composites based on 7xxx Al alloys had pronounced strength advantage over those based on pure $\mathrm{Al}$, 2xxx and 6xxx Al alloys [10, 26, 27], but the CNT/7xxx Al composites were rarely investigated. In this study, $7055 \mathrm{Al}$ alloy, a kind of high-strength $\mathrm{Al}$ alloy widely used in aircraft industry as upper wings, truss and horizontal stabilizer [28, 29], was selected as the matrix alloy. Two powder morphology evolution processes with different process characteristics were designed in HEBM. The dispersion, damage of CNTs as well as the composite tensile properties under both conditions were investigated. The aims are to reveal (a) the contribution of each HEBM stage to the dispersion of CNTs, and (b) the influence of various HEBM stages on the damage degree of CNTs.

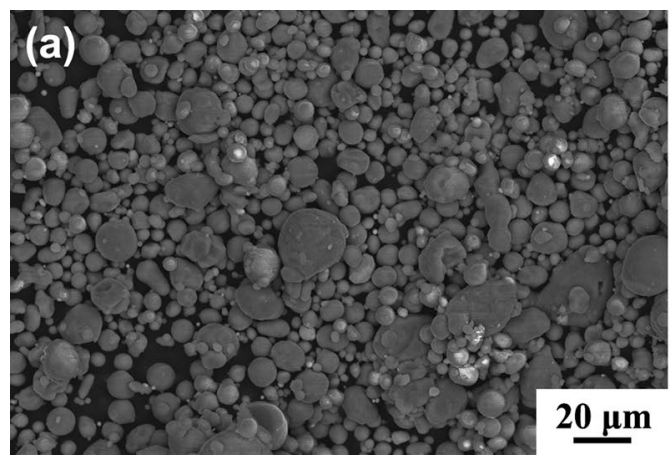

\section{Experimental}

The as-received $7055 \mathrm{Al}$ alloy powders with chemical composition of Al-8.1 wt $\% \mathrm{Zn}-2.2 \mathrm{wt} \% \mathrm{Mg}-2.2 \mathrm{wt} \% \mathrm{Cu}$ had an average diameter of about $10 \mu \mathrm{m}$ (Fig. 1a). The as-received multi-walled CNTs with diameters of 10-15 nm and lengths of about $5 \mu \mathrm{m}$ were provided by Cnano Technology Ltd. (Jiangsu, China) (Fig. 1b). 7055Al alloy powders were ball milled with 1 vol.\% CNTs using an attritor with a rotation rate of $400 \mathrm{rpm}$ for $6 \mathrm{~h}$. The total powder mixture was $1000 \mathrm{~g}$ and the ball-to-powder ratio was 15:1. Stainless steel balls with an average diameter of $5 \mathrm{~mm}$ were used as milling media, and argon gas was used as inert gas protection to prevent powder oxidation. A total of $1.6 \mathrm{wt} \%$ stearic acid (SA) was added to the powders as a process control agent (PCA).

Two powder morphology evolution processes were controlled by adding SA in two ways: (a) whole of the $1.6 \mathrm{wt} \%$ SA was added into the powder mixture prior to milling (HEBM-1); (b) $1 \mathrm{wt} \%$ SA was added into the powder mixture prior to milling and $0.3 \mathrm{wt} \%$ SA was added every $2 \mathrm{~h}$ (HEBM-2). For comparison, the $7055 \mathrm{Al}$ powders without CNTs were subjected to the same HEBM process.

The milled powders were cold compacted in a cylinder die, degassed at $400{ }^{\circ} \mathrm{C}$ for $2 \mathrm{~h}$ and then hot-pressed at $500{ }^{\circ} \mathrm{C}$ for $1.5 \mathrm{~h}$ under vacuum of about $10^{-1} \mathrm{~Pa}$ to form cylinder billets $(\Phi 50 \mathrm{~mm} \times 60 \mathrm{~mm})$. The as-pressed billets were hot extruded at $420{ }^{\circ} \mathrm{C}$ into bars with an extrusion ratio of $17: 1$. Finally, the extrusion rods were solution treated at $470{ }^{\circ} \mathrm{C}$ for $1 \mathrm{~h}$ followed by water quenching and aged at $120^{\circ} \mathrm{C}$ for $24 \mathrm{~h}$ (T6 treatment).

About $5 \mathrm{~g}$ powders were taken out from the attritor jar after every $2 \mathrm{~h}$ ' milling for examinations. The thickness of powders was observed by optical microscopy (OM, Axio Observer Z1). Field emission scanning electron microscopy (FE-SEM, SUPRA 55) was utilized to examine powder morphology and CNT distribution. For further analysing the dispersion of CNTs, the composites were sectioned along the extrusion direction and observed by transmission electron

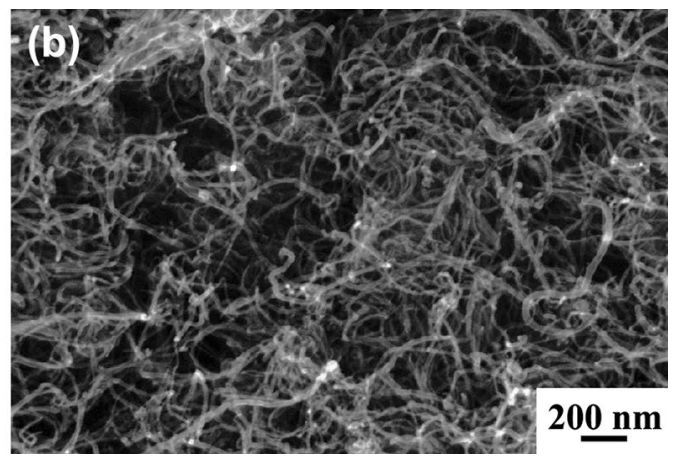

Fig. 1 Morphologies of as-received powders: a 7055Al powders and b CNTs 
microscopy (TEM, FEI, Tecnai Spirit T12). TEM specimens were cut by electrical discharge machining, ground to a thickness of $40 \mu \mathrm{m}$, pitted and finally ion-beam thinned by a Gatan PIPS 691 ion milling system at a voltage of $4.5 \mathrm{kV}$. In order to evaluate the damage of CNTs, Raman spectroscopic examination was performed on powder specimens by using a micro-Raman spectroscope (Jobin-Yvon HR800, excited by $532 \mathrm{~nm}$ He-Ne laser with laser size of $\sim 1 \mu \mathrm{m}^{2}$ ) in the spectral range from 600 to $2000 \mathrm{~cm}^{-1}$.

Dog-bone tensile specimens with a gauge diameter of $3 \mathrm{~mm}$ and a length of $15 \mathrm{~mm}$ were machined from the extruded rods. Tensile tests were carried out on an Instron 5982 tester at an initial strain rate of $1 \times 10^{-3} \mathrm{~s}^{-1}$ at room temperature. At least three specimens were tested for each composite.

\section{Results}

\subsection{Morphology Evolution of CNT/7055AI Powders During HEBM}

The morphologies of HEBM-1 and HEBM-2 CNT/7055Al powders are presented in Fig. 2. It shows that two powder morphology evolution processes were successfully achieved by adjusting SA addition. The HEBM-1 powders underwent a short flattening period at the first $2 \mathrm{~h}$ (Fig. 2a) and became cold-welded equiaxed shape at the end of $4 \mathrm{~h}$ (Fig. 2b). As the milling time further extended to $6 \mathrm{~h}$, the powders fractured with reduced size (Fig. 2c). The HEBM-2 powders became flaky at the first $2 \mathrm{~h}$ (Fig. 2d), and then turned to larger and thinner flakes with milling time prolonged to $4 \mathrm{~h}$ (Fig. 2e) and finally fractured into smaller flakes after milling for $6 \mathrm{~h}$ (Fig. 2f). It means that the HEBM-2 powders maintained the flaky morphology throughout the whole HEBM process.

Figure 3a shows the maximum dimension variations of HEBM-1 and HEBM-2 powders with milling time. After $2 \mathrm{~h}$ of milling, the maximum dimension of HEBM-1 powders increased from 10 to $76 \mu \mathrm{m}$, corresponding to the initial flattening of powders. As milling time increased from $2 \mathrm{~h}$ to $6 \mathrm{~h}$, the maximum dimension of HEBM-1 powders reduced from 76 to $25 \mu \mathrm{m}$. The maximum dimension of HEBM-2 powders increased from 10 to $120 \mu \mathrm{m}$ in the first $4 \mathrm{~h}$ and decreased to $56 \mu \mathrm{m}$ after $6 \mathrm{~h}$, which meant a large surface area for the HEBM- 2 powders during $2 \mathrm{~h}$ to $6 \mathrm{~h}$. The HEBM- 1 powders and HEBM-2 powders showed different trends in thickness variation, as shown in Fig. 3b. The thickness of HEBM-1 powders decreased after $2 \mathrm{~h}$ and quickly increased after $4 \mathrm{~h}$ and then decreased again. The thickness of HEBM-2 powders increased after $2 \mathrm{~h}$ and maintained about $4 \mu \mathrm{m}$ till the end, indicating that the cold-welding process was suppressed in this period.

\subsection{CNT Distribution on Powders During HEBM}

Figure 4 shows CNT distributions in the HEBM-1 and HEBM-2 powders. After $2 \mathrm{~h}$ of milling, CNT clusters were easily observed on surfaces of the HEBM-1 and HEBM-2 powders (Fig. 4a, d). As milling time increased, CNTs could hardly be observed except some outcropped CNTs due to cold-welding of the HEBM-1 powders, as shown in Fig. 4b, c. By comparison, large area of CNT agglomeration was found on surfaces of the HEBM-2 powders milled for 4 and $6 \mathrm{~h}$ (Fig. 4e, f). This demonstrated that CNTs were not dispersed well on flaky Al powders even after $6 \mathrm{~h}$ of milling.
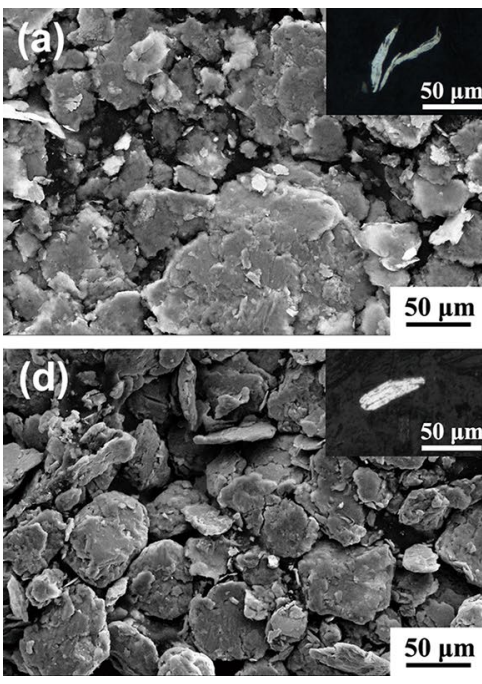
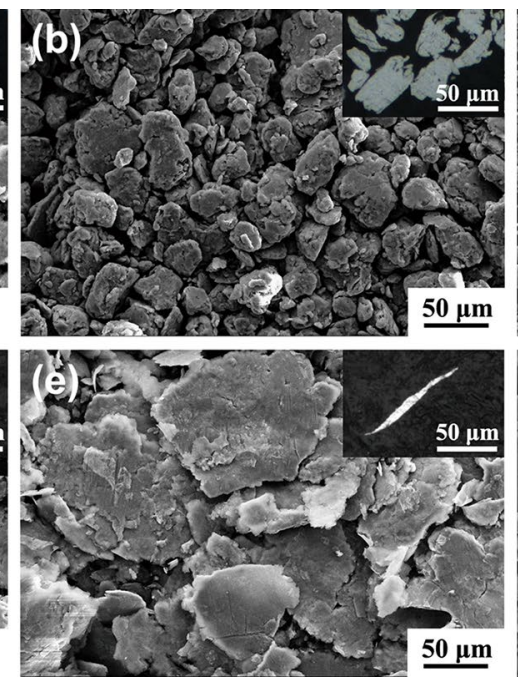
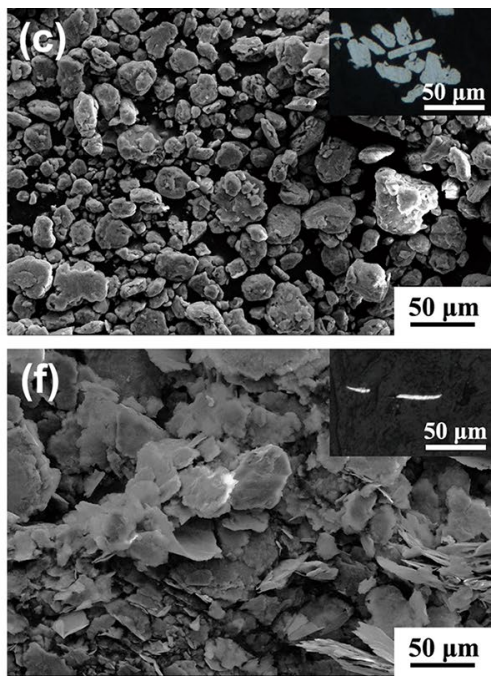

Fig. 2 SEM images of morphologies of HEBM-1 CNT/7055Al powders after milling for $\mathbf{a} 2 \mathrm{~h}, \mathbf{b} 4 \mathrm{~h}$ and $\mathbf{c} 6 \mathrm{~h}$, and HEBM-2 CNT/7055Al powders after milling for $\mathbf{d} 2 \mathrm{~h}, \mathbf{e} 4 \mathrm{~h}, \mathbf{f} 6 \mathrm{~h}$. (The insets taken by OM show the thickness of the powders) 
(a)

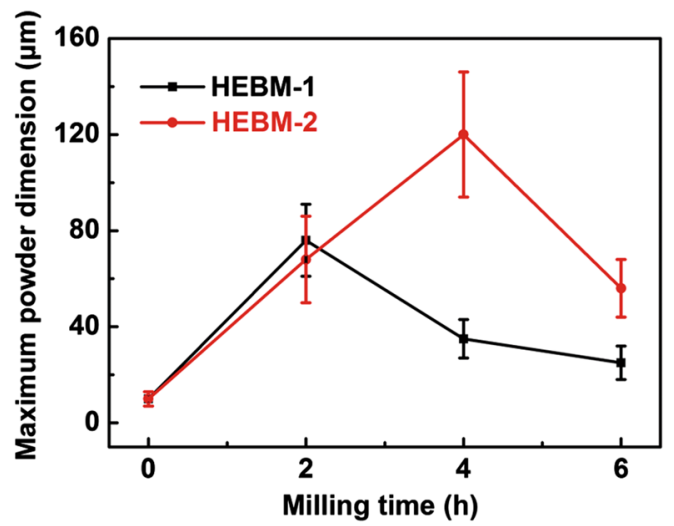

(b)

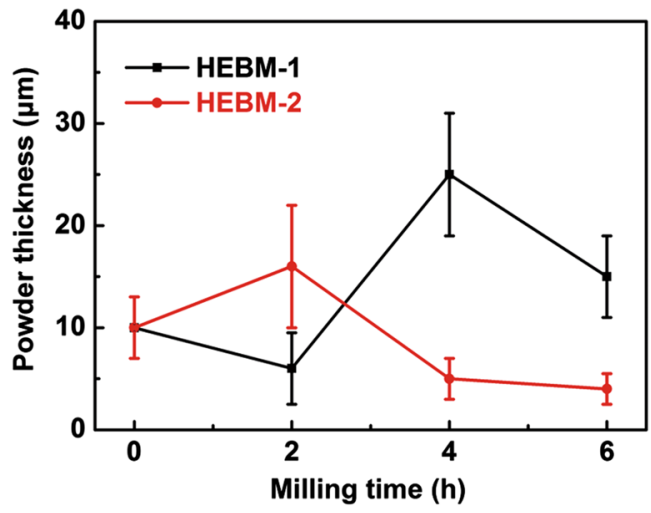

Fig. 3 a The maximum dimension and $\mathbf{b}$ thickness of HEBM-1 and HEBM-2 powders with milling time
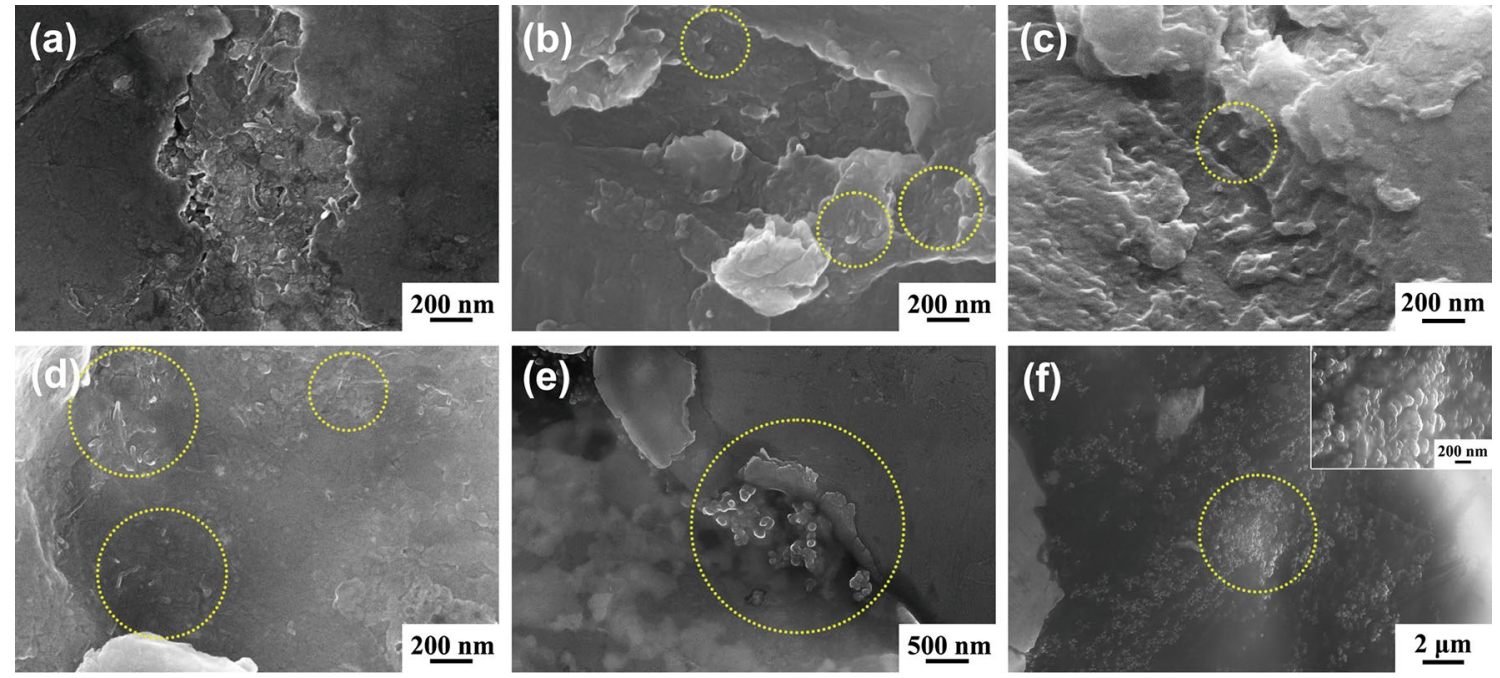

Fig. 4 SEM images of CNT distributions in the HEBM-1 powders after milling for a $2 \mathrm{~h}, \mathbf{b} 4 \mathrm{~h}$ and $\mathbf{c} 6 \mathrm{~h}$, and in the HEBM-2 powders after milling for $\mathbf{d} 2 \mathrm{~h}, \mathbf{e} 4 \mathrm{~h}, \mathbf{f} 6 \mathrm{~h}$. (CNTs are marked by yellow circles)

\subsection{TEM Observation of the CNT Dispersion}

TEM images of CNT distributions in the HEBM-1 and HEBM-2 CNT/7055Al composites are shown in Fig. 5. CNTs were almost singly dispersed in the HEBM-1 composite (Fig. 5a). However, a number of CNT clusters were observed in the HEBM-2 composite, although some dispersed CNTs could also be found (Fig. 5b). This indicates that the HEBM-1 powder evolution process was beneficial to CNT dispersion. The dispersed CNTs in the HEBM-1 composite had an average length of $100 \mathrm{~nm}$, which was much shorter than that of as-received CNTs. It demonstrates that the CNTs were sheared severely during the repetitive fracture and cold-welding of powders, which was in accordance with our previous investigation [9].

\subsection{Characterization of CNT Damage}

Figure 6 shows Raman spectra of HEBM-1 and HEBM-2 powders milled for different time. Two peaks in Raman spectra, the $\mathrm{D}\left(\sim 1350 \mathrm{~cm}^{-1}\right)$ band and $\mathrm{G}\left(\sim 1570 \mathrm{~cm}^{-1}\right)$ band are often used to characterize the structure of CNTs. The D band represents the presence of defects in graphite layers, and the $\mathrm{G}$ band represents highly crystalline graphite [21, 30]. Generally, the damage of CNTs can be evaluated by the intensity ratio of $\mathrm{D}$ band to $\mathrm{G}$ band $\left(I_{\mathrm{D}} / I_{\mathrm{G}}\right)$. As shown in Fig. 6, the as-received CNTs exhibited a $I_{\mathrm{D}} / I_{\mathrm{G}}$ value of 0.99 . For both HEBM- 1 and HEBM- 2 powders, variations in $I_{\mathrm{D}} / I_{\mathrm{G}}$ value with the milling time were similar. The $I_{\mathrm{D}} / I_{\mathrm{G}}$ ratios for both powders increased to a maximum value $(\sim 1.40)$ after $2 \mathrm{~h}$ of milling and then decreased to $\sim 1.27$ after $4 \mathrm{~h}$ of milling. As milling time increased to $6 \mathrm{~h}$, the $I_{\mathrm{D}} / I_{\mathrm{G}}$ ratios 

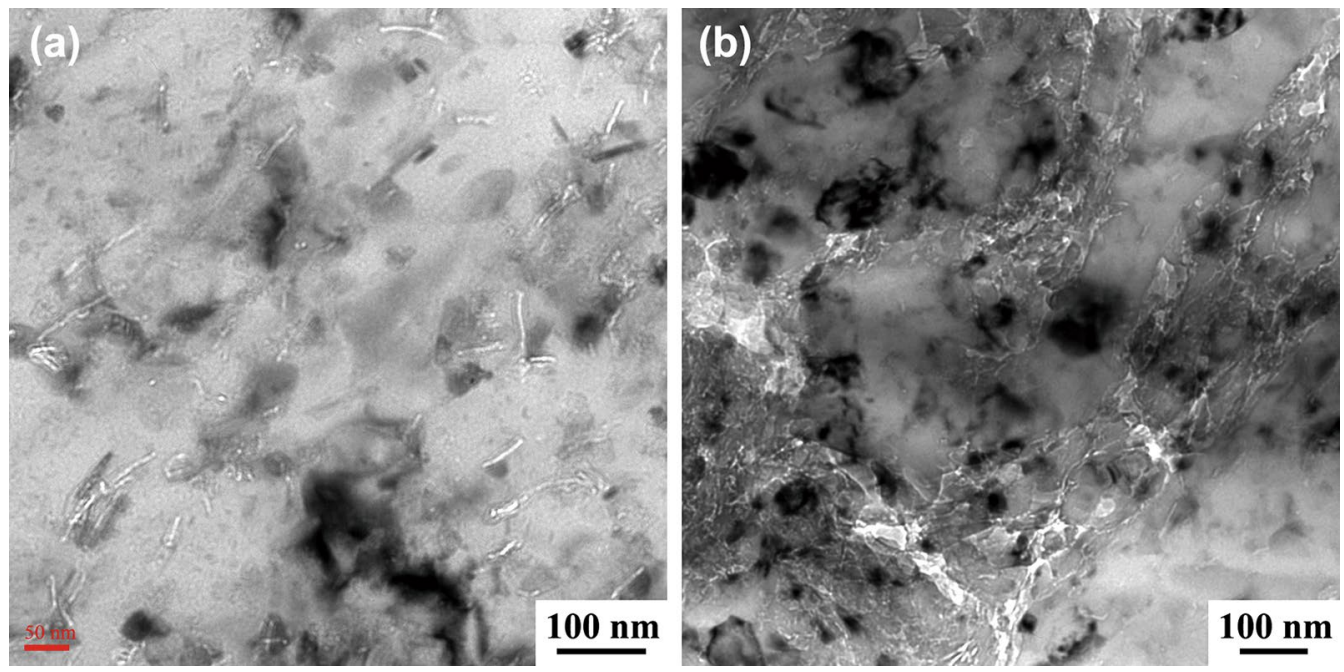

Fig. 5 TEM images of CNT distributions in CNT/7055Al composites fabricated from a HEBM-1 and b HEBM-2 powders milled for $6 \mathrm{~h}$

(a)

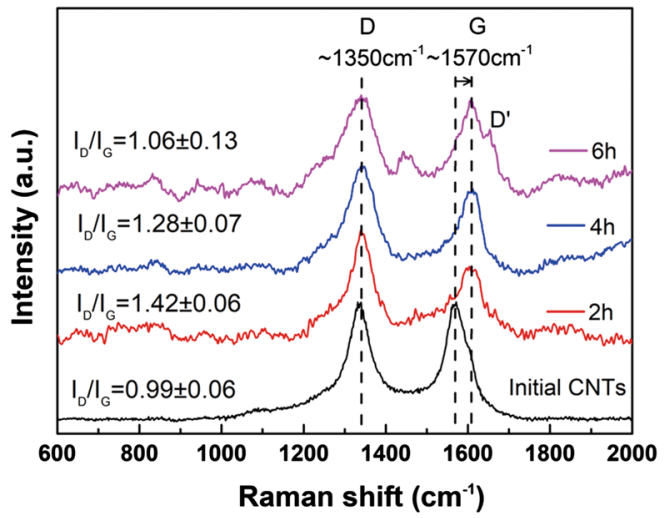

(b)

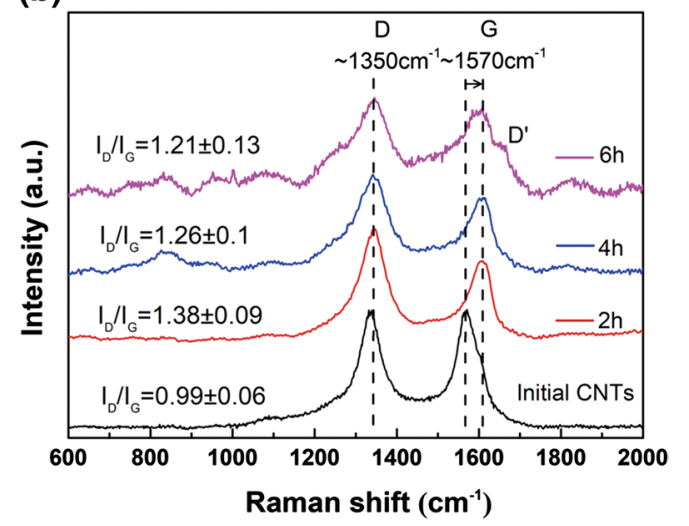

Fig. 6 Raman spectra of a HEBM-1 and b HEBM-2 CNT/7055Al powders milled for different time

further decreased to 1.06 and 1.21 for the HEBM- 1 and the HEBM-2 powders, respectively. In the first $2 \mathrm{~h}$, the increase in $I_{\mathrm{D}} / I_{\mathrm{G}}$ ratio indicated a certain degree of damage occurred to CNTs for both the powders. However, as milling time increased, the $I_{\mathrm{D}} / I_{\mathrm{G}}$ ratios of both powders decreased. This experimental result was conflicting with most of the previous reports [21, 23, 24]. A further explanation for this will be conducted in the discussion section.

It should be noted that the G band of CNTs in the two powders after $2 \mathrm{~h}$ milling moved to a larger wave number direction, compared to the as-received CNTs. This is usually thought to arise from the compressive strain in CNTs [31, 32]. Because CNTs had lower coefficient of thermal expansion than $\mathrm{Al}$, they would undergo compressive strain during the cooling process of HEBM if they were embedded in $\mathrm{Al}$ powders. Thus, the shift of $\mathrm{G}$ band suggested that most of the CNTs were fixed in Al powders after $2 \mathrm{~h}$ of milling.
This could also be confirmed in SEM images, as shown in Fig. 4a, d.

In addition, a peak at $\sim 1450 \mathrm{~cm}^{-1}$ was detected in the HEBM-1 powders milled for $6 \mathrm{~h}$, rather than in the HEBM-2 powders milled for the same time. This peak could be attributed to the existence of $\mathrm{MgO}$ [33-35]. As well known, there was an oxide layer on the surface of the as-received metal powders. And very small amount of oxygen could also be introduced during the milling process. It is believed that mechanical activation could be induced by milling. In HEBM-1, the process of repetitive fracture and cold-welding of powders would induce the mechanical activation effect, thereby accelerating the reaction of $\mathrm{Mg}$ element with oxides and finally forming the $\mathrm{MgO}$. However, in HEBM-2, cold-welding process was greatly suppressed, and the mechanical activation effect was significantly weakened. As a result, the $\mathrm{MgO}$ peak was 
not detected. The Raman spectrum of the HEBM-2 powders proved that the process of cold-welding was greatly restrained and the powders retained the flaky shape during the whole HEBM-2 process.

\subsection{Tensile Properties of CNT/7055AI Composites}

The typical engineering tensile stress-strain curves of the CNT/7055Al composites and relevant 7055Al matrices are shown in Fig. 7. The HEBM-1 composite exhibited an ultimate tensile strength (UTS) of $760 \mathrm{MPa}$ with an enhancement of $60 \mathrm{MPa}$ over the unreinforced alloy counterpart. However, the HEBM-2 composite showed a decrease of $30 \mathrm{MPa}$ in UTS as compared to that of the unreinforced alloy. The uniformly dispersed and agglomerated CNTs should be responsible for the strength results for the two composites. Although CNTs were sheared severely with significant reduction in length, the HEBM-1 composite exhibited a higher efficiency of load transfer strengthening than that of the HEBM-2 composite due to a much better uniform distribution of CNTs [1,9].

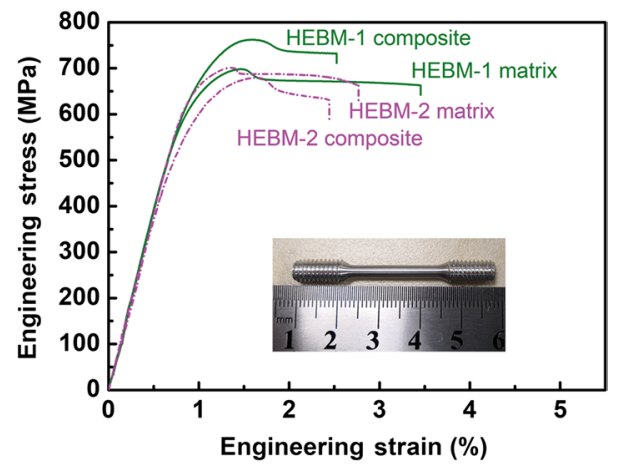

Fig. 7 Tensile curves of 1 vol.\% CNT/7055Al composites and $7055 \mathrm{Al}$ fabricated from HEBM-1 and HEBM-2 powders

\section{Discussion}

\subsection{CNT Dispersion During Different Powder Morphology Evolution Processes}

As described above, two powder morphology evolution processes, namely HEBM-1 and HEBM-2, were achieved. The HEBM-1 evolution, namely the "original spherical shape $\rightarrow$ flaky shape $\rightarrow$ cold-welding shape", was a conventional evolution process in HEBM. This evolution has been reported in many previous investigations [10, 20-23]. The HEBM-2 evolution, namely the "original spherical shape $\rightarrow$ flaky shape", was obtained by adding PCA in several times. According to the classical ball milling theory, the effect of PCA was to distribute on the surfaces of powders to prevent cold-welding. The SEM images in Fig. 2 and the Raman spectra in Fig. 6 demonstrate that the HEBM-2 powders retained the flaky shape during HEBM. The illustrations of CNT dispersion during HEBM-1 and HEBM-2 processes are shown in Fig. 8. During HEBM-1 process, the spherical powders became flattening and clustered CNTs were embedded in flaky Al powders in the first stage of HEBM. As milling time extended, the flaky $\mathrm{Al}$ powders began to cold-weld with each other. CNTs were then wrapped into Al powders during cold-welding process. With the milling process prolonged, fracture of cold-welded powders occurred due to hardening of $\mathrm{Al}$ powders. Through the effect of repetitive fracture and cold-welding of powders, CNT clusters inside the powders were broken, sheared and cut. Finally, CNTs with short length were singly dispersed.

HEBM-2 process could be regarded as an extension of the initial flattening stage in HEBM-1. During HEBM-2 process, the powder cold-welding process was greatly suppressed since PCA was added in each $2 \mathrm{~h}$ milling. The powders were flattened and became thinner in the initial stage of HEBM. As milling time increased, the powders were

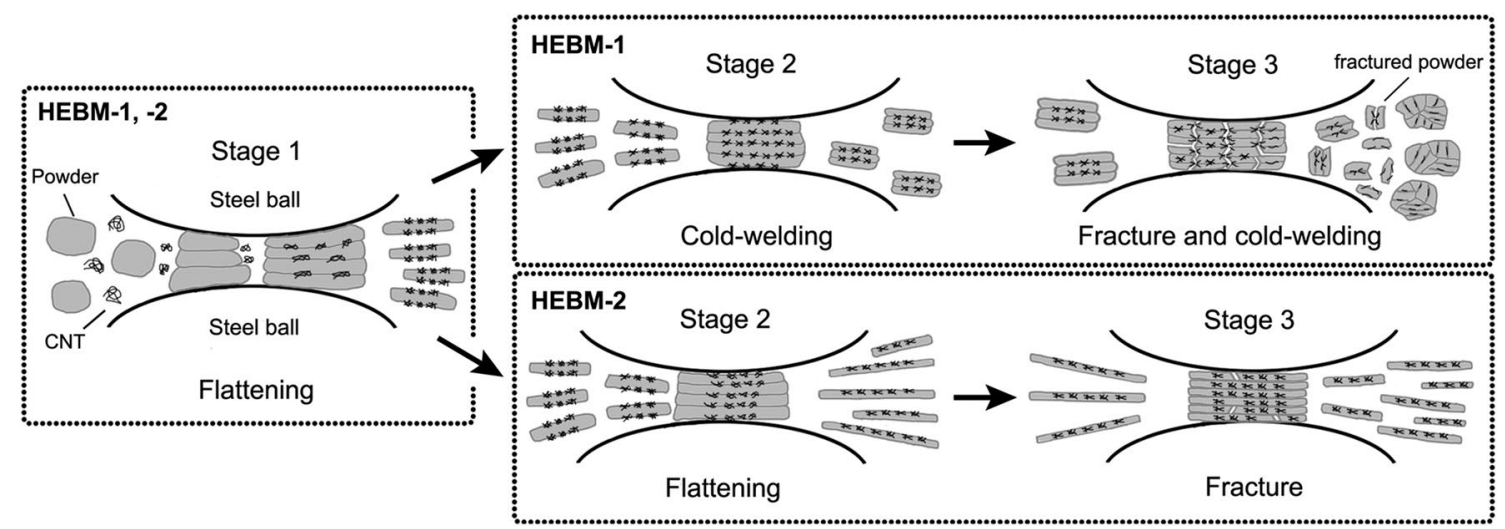

Fig. 8 Illustrations of CNT dispersion on Al powders during HEBM-1 and HEBM-2 evolution processes 
hardened and fractured at the end of milling. Since the CNTs were firmly embedded in powders after $2 \mathrm{~h}$ of milling, as evidenced in SEM images and Raman spectra (Figs. 4 and 6), the fracture process with suppressed cold-welding could not unravel CNT clusters. Our previous study [20] found that CNT clusters failed to be broken up under a high rotation rate $(450 \mathrm{rpm}$ ) during HEBM due to insufficient powder flattening. However, in HEBM-2 process, the flattening stage was pretty long $(\sim 6 \mathrm{~h})$, whereas the CNTs were still not dispersed uniformly. This proves that the cold-welding and fracture process helped to disperse clustered CNTs in the flaky $\mathrm{Al}$ powders.

Although the HEBM-2 powders experienced a long flattening time, the specific surface area was not large enough to fully accommodate dispersed CNTs. Assuming that a layer of singly dispersed CNTs was closely packed on flaky Al powders, the surface area of flaky powders was equal to that of CNT layers. The following equation could be achieved:

$\frac{V_{\mathrm{Al}}}{t_{\mathrm{Al}}}=\frac{V_{\mathrm{CNT}}}{d_{\mathrm{CNT}}}$,

where $V_{\mathrm{Al}}$ is the volume of flaky $\mathrm{Al}$ powders, $V_{\mathrm{CNT}}$ is the volume of CNTs, $t_{\mathrm{Al}}$ is the thickness of flaky powders and $d_{\mathrm{CNT}}$ is the diameter of CNTs. In this study, $V_{\mathrm{Al}}=99 V_{\mathrm{CNT}}$ and $d_{\mathrm{CNT}}$ is $\sim 10 \mathrm{~nm}$. The thickness of flaky $\mathrm{Al}$ powders for accommodating singly dispersed CNT was calculated to be $990 \mathrm{~nm}$. However, the minimum average thickness of flaky Al powders during milling for HEBM-2 powders was about $4 \mu \mathrm{m}$ (Fig. 2), which was much larger than the calculated critical value. Hence, CNTs could not be dispersed uniformly on flaky Al powders. Equation (1) could also be verified by investigation of $\mathrm{Xu}$ et al. [21]. They dispersed 2.2 vol.\% CNTs on ultra-thin flaky Al powders with an average thickness of $\sim 200 \mathrm{~nm}$ through ball milling at a relatively low speed of $135 \mathrm{rpm}$ for $8 \mathrm{~h}$. This thickness value was much less than the critical value (about $890 \mathrm{~nm}$ ) calculated using the parameters they provided, thereby producing uniformly dispersed CNTs. The above results indicate that the repetitive fracture and cold-welding process was also necessary for dispersing CNTs, if the thickness of flaky $\mathrm{Al}$ powders exceeded the critical value.

\subsection{Damage of CNTs During Different Powder Morphology Evolution Processes}

It is noted that the $I_{\mathrm{D}} / I_{\mathrm{G}}$ ratio reduced as milling time increased from 2 to $6 \mathrm{~h}$ for either HEBM-1 or HEBM-2 powders, which was not in accordance with common sense. Kwon et al. [36] who observed a similar result in a dualnanoparticulate reinforced $\mathrm{Al}$ alloy matrix composite suggested it as experimental error. However, since the decrease in $I_{\mathrm{D}} / I_{\mathrm{G}}$ ratio in the HEBM-1 powders was beyond the error bars, errors could not explain the present experimental phenomenon. A careful observation of the $\mathrm{G}$ band region in both HEBM- 1 and HEBM- 2 powders milled for $6 \mathrm{~h}$ revealed the presence of a second peak on the right side of $\mathrm{G}$ band, which refers to the D' Raman scatter band. It is reported that the D' band was also a characteristic peak in disordered graphite that arose from nonzero-centre phonons and related to peaks in the density of states [37-39]. The D' band on the right side of $\mathrm{G}$ band is usually at $1620 \mathrm{~cm}^{-1}$. However, it was shifted to $1650 \mathrm{~cm}^{-1}$ in both of the HEBM powders, which could be associated with the shift of $\mathrm{G}$ band. Travessa et al. [40] reported that the appearance of the D' band could lead to an increase in the $I_{\mathrm{G}}$ magnitude, thereby decreasing the $I_{\mathrm{D}} / I_{\mathrm{G}}$ ratio. Therefore, using $I_{\mathrm{D}} / I_{\mathrm{G}}$ ratio could not accurately assess the actual damage of the CNTs.

The presence of D' band was also observed in Antunes et al.'s study [41]. They found that $I_{\mathrm{D}} / I_{\mathrm{G}}$ ratio could not describe the damage of CNTs with different diameters and alignment directions. Considering that broadening of $\mathrm{D}$ band was expansion of defect domain size [42], Antunes et al. suggested that the product of $I_{\mathrm{D}} / I_{\mathrm{G}}$ and full width half maximum of D band (FWHM (D)) were more accurate than $I_{\mathrm{D}} / I_{\mathrm{G}}$. The broadening of $\mathrm{D}$ band with increasing milling time was also observed in the HEBM-1 and HEBM-2 powders, as shown in Fig. 6.

In this study, the product of $I_{\mathrm{D}} / I_{\mathrm{G}}$ and FWHM (D) was used to describe the CNT damage, and the results are shown in Fig. 9. The higher product values indicate more severe damage of CNTs. In accordance with the previous studies [23-25], the damage of CNTs increased with increasing milling time for both of HEBM- 1 and HEBM-2 powders. During HEBM-1, the damage of CNTs increased dramatically in the first $2 \mathrm{~h}$ of milling. As shown in Fig. 4, most of the CNTs were located on the surfaces of Al powders and they underwent severe shear effect in this stage. As milling time increased from $2 \mathrm{~h}$ to $4 \mathrm{~h}$, the damage of CNTs was

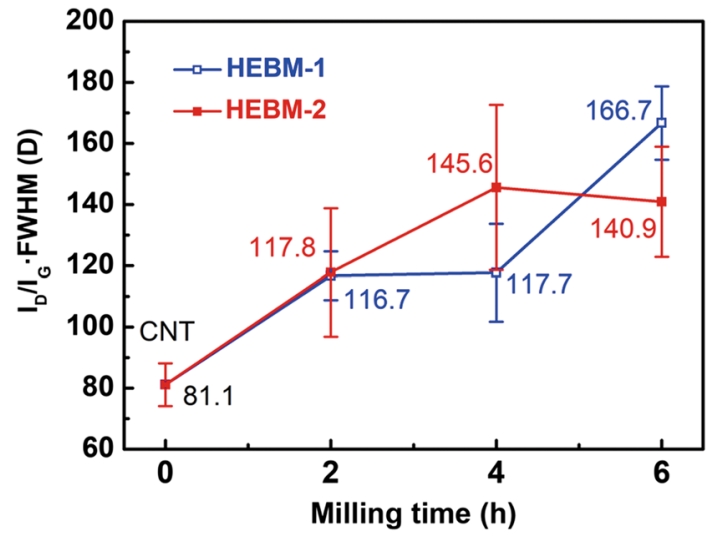

Fig. 9 Variations in product of $I_{\mathrm{D}} / I_{\mathrm{G}}$ and FWHM (D) with milling time during HEBM-1 and HEBM-2 evolution processes 
slight as compared to the initial flattening stage of $\mathrm{Al}$ powders. It is believed that the CNTs were wrapped by flaky Al powders due to cold-welding in this stage, and thus escaped the severe mechanical effect of milling. At the last $2 \mathrm{~h}$ milling, the damage of CNTs increased significantly again. This is because CNTs were severely cut due to fracture of the cold-welded powders.

During HEBM-2, the damage of CNTs during the initial $2 \mathrm{~h}$ was similar to that in HEBM-1. After milling for $4 \mathrm{~h}$, the CNTs continued to be damaged because CNTs were still located on the surfaces of flaky Al powders instead of being wrapped by cold-welded Al powders. In this period, with the surface area increase and thickness reduction of the flaky $\mathrm{Al}$ powders, more CNTs were exposed to milling balls and led to continuously increased damage. As milling time increased from $4 \mathrm{~h}$ to $6 \mathrm{~h}$, the damage of CNTs nearly remained stable. This is because the CNTs were embedded inside powders after several hours of milling (Fig. 4f) and avoided damage.

\section{Conclusions}

1. Two powder morphology evolution processes (HEBM-1 and HEBM-2) were achieved by controlling the adding times and amount of PCA during HEBM in fabrication of CNT/7055Al composite powders. In HEBM-1, the powders flattened, cold-welded and fractured. In HEBM-2, powder cold-welding was suppressed. Powders flattened, maintained flaky shape and fractured.

2. CNTs were uniformly dispersed with significant length reduction during HEBM-1, while CNTs were hardly dispersed during HEBM-2. Powder flattening process was ineffective in dispersing CNTs in HEBM-2 because the thickness of flaky Al powders exceeded the critical value and CNTs were fixed on the surfaces of flaky Al powders. Repetitive powder fracture and cold-welding process was considered as the main pattern for dispersing CNTs in HEBM-1.

3. Product of $I_{\mathrm{D}} / I_{\mathrm{G}}$ and FWHM (D), rather than $I_{\mathrm{D}} / I_{\mathrm{G}}$, was used to characterize the structural damage of CNTs. It indicates that the damage of CNTs was severe in the stages of powder flattening and fracture, while cold welding stage led to little damage to CNTs.

\footnotetext{
Acknowledgements This work was supported by the Key Research Program of Frontier Sciences, CAS (No. QYZDJ-SSW-JSC015); the National Key R\&D Program of China (No. 2017YFB0703104); the Project of manned spaceflight (No. 040103); the National Natural Science Foundation of China (Nos. 51931009, 51871215); the Youth Innovation Promotion Association CAS (No. 2020197). We also thank very much to Li Zhang for providing support on scanning electron microscopy.
}

\section{References}

[1] C. Wang, B.B. Wang, D. Wang, P. Xue, Q.Z. Wang, B.L. Xiao, L.Q. Chen, Z.Y. Ma, Acta Metall. Sin. (Engl. Lett.) 32, 677 (2019)

[2] Z.Y. Liu, B.L. Xiao, W.G. Wang, Z.Y. Ma, J. Mater. Sci. Technol. 30, 649 (2014)

[3] X.J. Zhang, Z.K. Dai, X.R. Liu, W.C. Yang, M. He, Z.R. Yang, Acta Metall. Sin. (Engl. Lett.) 31, 761 (2018)

[4] Z.W. Zhang, Z.Y. Liu, B.L. Xiao, D.R. Ni, Z.Y. Ma, Carbon 135, $215(2018)$

[5] Z.Y. Yu, Z.Q. Tan, G.L. Fan, R.B. Lin, D.B. Xiong, Q. Guo, Y.S. Su, Z.Q. Li, D. Zhang, Acta Metall. Sin. (Engl. Lett.) 31, 1121 (2018)

[6] D. Qian, G.J. Wagner, W.K. Liu, M.-F. Yu, R.S. Ruoff, Appl. Mech. Rev. 55, 495 (2002)

[7] J.P. Salvetat-Delmotte, A. Rubio, Carbon 40, 1729 (2002)

[8] Z.Y. Liu, K. Ma, G.H. Fan, K. Zhao, J.F. Zhang, B.L. Xiao, Z.Y. Ma, Carbon 157, 602 (2020)

[9] Z.Y. Liu, B.L. Xiao, W.G. Wang, Z.Y. Ma, Acta Metall. (Sin. Engl. Lett.) 27, 901 (2014)

[10] A. Esawi, K. Morsi, Compos. Part A 38, 646 (2007)

[11] L. Ci, Z. Ryu, N.Y. Jin-Phillipp, M. Rühle, Acta Mater. 54, 5367 (2006)

[12] K. Zhao, Z.Y. Liu, B.L. Xiao, D.R. Ni, Z.Y. Ma, Acta Metall. Sin. (Engl. Lett.) 31, 134 (2018)

[13] Z.Y. Liu, K. Zhao, B.L. Xiao, W.G. Wang, Z.Y. Ma, Mater. Des. 97, 424 (2016)

[14] G. Fan, R. Xu, Z. Tan, D. Zhang, Z. Li, Acta Metall. Sin. (Engl. Lett.) 27, 806 (2014)

[15] D.H. Nam, S.I. Cha, B.K. Lim, H.M. Park, D.S. Han, S.H. Hong, Carbon 50, 2417 (2012)

[16] D.H. Nam, Y.K. Kim, S.I. Cha, S.H. Hong, Carbon 50, 4809 (2012)

[17] X. Yang, T. Zou, C. Shi, E. Liu, C. He, N. Zhao, Mater. Sci. Eng. A 660, $11(2016)$

[18] C. He, N. Zhao, C. Shi, X. Du, J. Li, H. Li, Q. Cui, Adv. Mater. 19, 1128 (2007)

[19] L. Jiang, G. Fan, Z. Li, Z. Li, X. Kai, D. Zhang, Z. Chen, S. Humphries, G. Heness, W.Y. Yeung, Carbon 49, 1965 (2011)

[20] Z.Y. Liu, B.L. Xiao, W.G. Wang, Z.Y. Ma, Compos. Part A 94, 189 (2017)

[21] R. Xu, Z. Tan, D. Xiong, G. Fan, Q. Guo, J. Zhang, Y. Su, Z. Li, D. Zhang, Compos. Part A 96, 57 (2017)

[22] H.J. Choi, J.H. Shin, D.H. Bae, Compos. Part A 43, 1061 (2012)

[23] Z.Y. Liu, S.J. Xu, B.L. Xiao, P. Xue, W.G. Wang, Z.Y. Ma, Compos. Part A 43, 2161 (2012)

[24] X. Liu, C. Li, J. Eckert, K.G. Prashanth, O. Renk, L. Teng, Y. Liu, R. Bao, J. Tao, T. Shen, J. Yi, Mater. Charact. 133, 122 (2017)

[25] A. Kumar, M.K. Banerjee, U. Pandel, Powder Technol. 331, 41 (2018)

[26] H.J. Choi, B.H. Min, J.H. Shin, D.H. Bae, Compos. Part A 42, 1438 (2011)

[27] M. Chen, G. Fan, Z. Tan, D. Xiong, Q. Guo, Y. Su, J. Zhang, Z. Li, M. Naito, D. Zhang, Mater. Des. 142, 288 (2018)

[28] K. Chen, H. Liu, Z. Zhang, S. Li, R.I. Todd, J. Mater. Process. Technol. 142, 190 (2003)

[29] T.S. Srivatsana, S. Anand, S. Sriram, V.K. Vasudevan, Mater. Sci. Eng. A 281, 292 (2000)

[30] M.S. Dresselhaus, G. Dresselhaus, R. Saito, A. Jorio, Phys. Rep. 409, 47 (2005)

[31] O. Lourie, H.D. Wagner, J. Mater. Res. 13, 2418 (1998)

[32] C. Galiotis, D.N. Batchelder, J. Mater. Sci. 7, 545 (1988)

[33] I.F. Mironyuk, V.M. Gunko, M.O. Povazhnyak, V.I. Zarko, V.M. Chelyadin, R. Leboda, J. Skubiszewska-Zięba, W. Januszc, Appl. Surf. Sci. 252, 4071 (2006) 
[34] K. Ishikawa, N. Fujima, H. Komura, J. Appl. Phys. 57, 983 (1985)

[35] N.B. Manson, W. Von der Ohe, S.L. Chodos, Phys. Rev. B 3, 1968 (1971)

[36] H. Kwon, M. Saarna, S. Yoon, A. Weidenkaff, M. Leparoux, Mater. Sci. Eng. A 590, 338 (2014)

[37] J. Kastner, T. Pichler, H. Kuzmany, S. Curran, W. Blau, D.N. Weldon, M. Delamesiere, S. Draper, H. Zandbergen, Chem. Phys. Lett. 221, 53 (1994)

[38] R.P. Vidano, D.B. Fischbach, L.J. Willis, T.M. Loehr, Solid State Commun. 39, 341 (1981)
[39] P. Lespade, R. Al-Jishi, M.S. Dresselhaus, Carbon 20, 427 (1982)

[40] D.N. Travessa, M. Lieblich, Mater. Sci. Forum 802, 90 (2014)

[41] E.F. Antunes, A.O. Lobo, E.J. Corat, V.J. Trava-Airoldi, Carbon 45, 913 (2007)

[42] E.B. Barros, N.S. Demir, A.G. Souza Filho, J. Mendes Filho, A. Jorio, G. Dresselhaus, M.S. Dresselhaus, Phys. Rev. B 71, 16422 (2005) 